\title{
Proteomic analysis of non-tumoral breast tissue
}

\author{
G.G. Costa ${ }^{1}$, R. Kaviski ${ }^{1}$, L.E.R. Souza ${ }^{2}$, C.A. Urban ${ }^{3}$, R.S. Lima ${ }^{3}$, \\ I.J. Cavalli ${ }^{1}$ and E.M.S.F. Ribeiro ${ }^{1}$ \\ 'Departamento de Genética, Universidade Federal do Paraná, \\ Curitiba, PR, Brasil \\ ${ }^{2}$ Departamento de Patologia Básica, Universidade Federal do Paraná, \\ Curitiba, PR, Brasil \\ ${ }^{3}$ Unidade da Mama, Hospital Nossa Senhora das Graças, Curitiba, PR, Brasil \\ Corresponding author: E.M.S.F. Ribeiro \\ E-mail: eribeiro@ufpr.br
}

Genet. Mol. Res. 10 (4): 2430-2442 (2011)

Received March 24, 2011

Accepted September 6, 2011

Published October 3, 2011

DOI http://dx.doi.org/10.4238/2011.October.3.3

\begin{abstract}
Breast cancer is a complex and heterogeneous disease. In spite of the advances made in recent decades, a better understanding of the intrinsic mechanisms of this disease is crucial. The development of new biomarkers is absolutely necessary to improve diagnosis and prognosis. Research using the proteomic approach has generated interesting results; however, the complexity of the mammary gland and of breast tumors remains a major limitation to the development of new markers. An initial step is to characterize non-tumoral human breast tissue. We present data from classical proteomic analysis based on 2-D electrophoresis and peptide mass fingerprinting identification, which were performed on six non-tumoral samples from patients with invasive ductal breast carcinomas. Forty-four different proteins from 70 spots were identified and classified according to their biological function. Cytoskeleton and associated proteins represent the largest class $(30 \%)$ followed by the proteins with binding function $(27 \%)$. Several of the proteins have been described in breast tumors, such as vimentin, endoplasmin, small heat shock beta- 6 , disulfide isomerase
\end{abstract}


and some cell growth, and proliferation regulators, suggesting the importance of including data on the characterization of non-tumoral breast and to studies on differential expression in cancer tissue.

Key words: Non-tumoral breast tissue; Proteomics; Biomarkers

\section{INTRODUCTION}

Breast tissue is controlled by a complex system of hormones (estrogens, progesterone) acting through their respective receptors, as well as a number of local factors from its microenvironment (growth factors). During life, mammary epithelium undergoes repeated cycles of growth, differentiation, and regression, with correlated changes in morphology and metabolism. The anatomic structures are modified by age, menstrual state, pregnancy, and hormonal replacement therapy. The repeated development and involutional changes of menstruation and pregnancy that occur between 15 and 50 years of age create abundant opportunities for minor aberrations to occur (Courtillot et al., 2005). The normal human breast gland is comprised of a branching ductal-lobular system lined by an inner layer of luminal epithelial cells and an outer layer of myoepithelial cells that are separated from the interstitial stroma by an intact basement membrane. The luminal epithelial cells are polarized glandular cells with specialized apical and basolateral membrane domains expressing sialomucin and cell-cell adhesion molecules, respectively. The myoepithelial cells contribute significantly to the formation of basement membrane, and their myogenic differentiation is responsible for the contractile function (Toillon et al., 2007). Because alterations in breast structure and function throughout life can predispose this tissue to the development of breast cancer (Navarrete et al., 2005), understanding the factors and mechanisms that regulate hormone-related changes in the normal human breast is essential. Proteomics is a promising approach for addressing both the development of complementary methods to detect and classify breast cancer in early stages and molecular markers to determine the outcome (Hondermarck et al., 2008, Moreira et al., 2010). A first step towards achieving this goal will be the definition of the phenotypes that exist in the normal breast (Lopez-Garcia et al., 2010). In order to contribute to the knowledge of the non-tumoral profile, we gathered data on six samples; 44 proteins were identified from 70 spots and grouped into categories based on their major biological functions (Pucci-Minafra et al., 2006): cytoskeleton and associated proteins, proteins with binding function, metabolic enzymes, molecular chaperones/heat shock proteins, detoxification and redox proteins, membrane-associated proteins with multiple activities, cell growth and proliferation regulators, protein degradation, and other functions.

\section{MATERIAL AND METHODS}

\section{Sample characterization and protein extraction}

Aliquots of non-tumoral breast tissue samples were obtained during the surgeries of six female patients (mean age $60.16 \pm 10.94$ years). All patients were affected with invasive ductal breast cancer, five were classified as grade II and one as grade I. The study was approved by the local Ethics Committee from the Nossa Senhora das Graças Hospital (Curitiba, Brazil) and the patients signed an informed consent. 
The tissue was removed from the contralateral side of the tumor respecting the safety margin, which is at least $5 \mathrm{~cm}$ from the tumor. The absence of tumor cells, as well as the histological diagnosis and tumor grade, were confirmed by a pathologist.

The samples were immediately transferred to the laboratory, where $400 \mathrm{mg}$ tissue was submerged in a lysis solution ( $7 \mathrm{M}$ urea, $2 \mathrm{M}$ thiourea, 4\% CHAPS, $40 \mathrm{mM}$ Tris, and $0.2 \%$ PMSF). Lysates were kept on ice for $30 \mathrm{~min}$, followed by homogenization with an electric tissue disruptor, and $10 \mathrm{~min}$ in a refrigerated centrifuge at 12,000 rpm. The supernatants were collected and stored at $-80^{\circ} \mathrm{C}$ until use. The protein concentration was determined by the Bradford method (Bradford, 1976).

\section{2-D gel electrophoresis}

Isoelectric focusing (IEF) was performed with precast $13 \mathrm{~cm}$ IPG strips (pH 4-7, 130 x 3 x $0.5 \mathrm{~mm}$; GE Healthcare) using an Ettan IPGphor II (GE Healthcare). The cell lysate (1000 $\mu \mathrm{g}$ proteins) was mixed with rehydration buffer (7 M urea, $2 \mathrm{M}$ thiourea, $2 \%$ CHAPS, adding $50 \mathrm{mM}$ DTT and $0.5 \%$ IPG buffer) totaling $250 \mu \mathrm{L}$. Rehydration occurred at room temperature for $16 \mathrm{~h}$ in the Immobiline DryStrip Reswelling Tray (GE Healthcare). The strips were placed on a ceramic plate (Manifold/GE Healthcare) and IEF was performed under the following conditions: 1) $500 \mathrm{~V}$ for $1 \mathrm{~h}$; 2) $100 \mathrm{~V}$ for $1 \mathrm{~h}$; 3) $8000 \mathrm{~V}$ for 2:30 h; 4) $8000 \mathrm{~V}$ for $30 \mathrm{~min}$. After IEF, the strips were equilibrated for $15 \mathrm{~min}$ in a buffer containing $50 \mathrm{mM}$ Tris$\mathrm{HCl}, \mathrm{pH} 8.8 ; 6 \mathrm{M}$ urea; $30 \%(\mathrm{w} / \mathrm{v})$ glycerol and 2\% (w/v) SDS and $50 \mathrm{mM}$ DTT with traces of bromophenol blue. Free thiol groups were alkylated for $15 \mathrm{~min}$ in the same solution containing $4.5 \%$ iodoacetamide. Equilibrated strips were placed on the top of an SDS polyacrylamide gel $(10 \%, 18 \times 16 \mathrm{~cm})$ and sealed with $1 \%$ agarose containing traces of bromophenol blue.

SDS-PAGE was performed at Hoefer SE 600 Ruby in a running buffer $(25 \mathrm{mM}$ Tris, $192 \mathrm{mM}$ glycine and $0.1 \% \mathrm{SDS}$ ) (GE Healthcare) at $11^{\circ} \mathrm{C}$ for $30 \mathrm{~min}$ at $15 \mathrm{~mA}$ and for about $4.5 \mathrm{~h}$ at $30 \mathrm{~mA}$ until the bromophenol blue line was around $1 \mathrm{~cm}$ from the bottom.

\section{Gel staining, scanning and image analysis}

After 2-D gel electrophoresis, gels were kept about $1 \mathrm{~h}$ in a fixation solution $(1.3 \%$ orthophosphoric acid (85\%) and $20 \%$ methanol). Gels were stained with a solution containing $1.5 \%$ orthophosphoric acid (85\%), 7.7\% ammonium sulfate and $0.01 \%$ Coomassie G-250. The stained gels were scanned with ImageScanner ${ }^{\mathrm{TM}}$ II (GE Healthcare) and analyzed with ImageMaster $^{\mathrm{TM}}$ 2D Platinum v6.0 (GE Healthcare).

\section{MS analysis and protein identification}

The selected stained spots were excised from the gel followed by destaining with 50 $\mathrm{mM} \mathrm{NH} \mathrm{HCO}_{3}$ and $50 \%$ acetonitrile. The supernatant was removed and gel pieces were completely dried at room temperature. The excised spots were then rehydrated in $15 \mu \mathrm{L}$ digestion buffer containing $40 \mathrm{mM} \mathrm{NH}_{4} \mathrm{HCO}_{3}, 10 \%$ acetonitrile and $15 \mathrm{ng} / \mu \mathrm{L}$ trypsin (Sequencing Grade Modified Trypsin; Promega) in an ice-cold bath for $30 \mathrm{~min}$. The digestion was performed at $37^{\circ} \mathrm{C}$ overnight. The resulting peptides from the digests were mixed (1:1) with $50 \%$ acetonitrile and $0.1 \%$ trifluoroacetic acid saturated with HCCA matrix and spotted onto the MALDI targets. 
MALDI-TOF mass spectra were recorded on a MALDI-TOF/TOF/MS/MS AutoflexII (Bruker Daltonics, Leipzig, Germany) mass spectrometer, in the 800-3200 Da mass range using a minimum of 250 shots of laser per spectrum. Delayed extraction source $(150 \mathrm{~ns})$ and reflector equipment allowed sufficient resolution to consider $\mathrm{MH}^{+}$of monoisotopic peptide masses. The TOF acceleration voltage was $20 \mathrm{kV}$. MALDI mass data were externally calibrated with a peptide calibration standard kit. Internal calibration was done using trypsin autolysis fragments at $\mathrm{m} / \mathrm{z}$ of 842.52, 1045.56 and 2211.10 Da. Peptide mass fingerprinting was compared to the theoretical masses from the Swiss-Prot database using MASCOT (http://www.expasy.org/tools/). The search was done by restricting the taxonomic category to Homo sapiens. Typical search parameters were as follows: maximum 200 ppm of mass tolerance; carbamidemethylation of cysteine residues; one missed enzymatic cleavage for trypsin; a minimum of four-peptide mass hits were required for a match; methionine residues were considered to be in an oxidized form. Protein identifications were considered to be reliable when the protein score of the hit exceeded the threshold significance score of $56(\mathrm{P}<0.05)$ and no less than four peptides were recognized.

\section{RESULTS AND DISCUSSION}

The main objective of cancer proteome science is to define patterns of protein expression from tissues originating under different conditions (healthy, benign diseases, different types and stages of cancer, metastasis) that are useful for basic and applied research applications (PucciMinafra et al., 2006). We examined six samples obtained from patients with invasive ductal breast cancer, which were collected respecting the safety margin (at least $5 \mathrm{~cm}$ from the tumor) and free of cancer cells. Three bidimensional gels were made for each sample and a reference gel was chosen based on the representation and resolution of the spots. The six reference gels were then analyzed to choose the master reference gel (Figure 1), in which the protein spots are identified with the abbreviated name of the Swiss-Prot database. Using the ImageMaster ${ }^{\mathrm{TM}}$ 2D Platinum v6.0 software, we detected 118 spots, which were present in the master and in at least two of the other five reference gels. Of the 118 spots, 70 were identified, corresponding to 44 different proteins (Table 1). Comparing the theoretical and the observed value of the molecular weight (MW) and $\mathrm{pI}$ of each protein, we noticed that the majority $(76 \%)$ was identified at the expected position on the gels ( $\Delta \mathrm{MW}<20 \%$ and $\Delta \mathrm{pI}<0.6$, according to Dupont et al., 2005). Approximately, $30 \%$ of the 44 identified proteins were represented by more than one spot, suggesting the occurrence of post-translational modifications, such as acetylation, phosphorylation and glycosylation (Ramos and Bora, 2004; Mayr et al., 2005; Zhu et al., 2005; Löster and Kannicht, 2008).

Through the information obtained from literature and NCBI (http://www.ncbi.nlm. nih.gov/) and UniProtKB/Swiss-Prot (http://www.expasy.ch/) databases, the 44 identified proteins were separated according to their main biological functions into nine classes (Figure 2): 1) cytoskeleton and associated proteins; 2) proteins with binding function; 3 ) metabolic enzymes; 4) molecular chaperones/heat shock proteins; 5) detoxification and redox proteins; 6) membrane-associated proteins with multiple activities; 7) cell growth and proliferation regulators; 8) protein degradation, and 9) other functions. These classes were based on a study by Pucci-Minafra et al. (2006). In spite of this functional classification, these classes should be treated with caution. We agree with the authors that the organization of proteins into functional categories is fundamental to better understanding the mechanisms and the biochemical functions of cells and their involvement in cancer. 


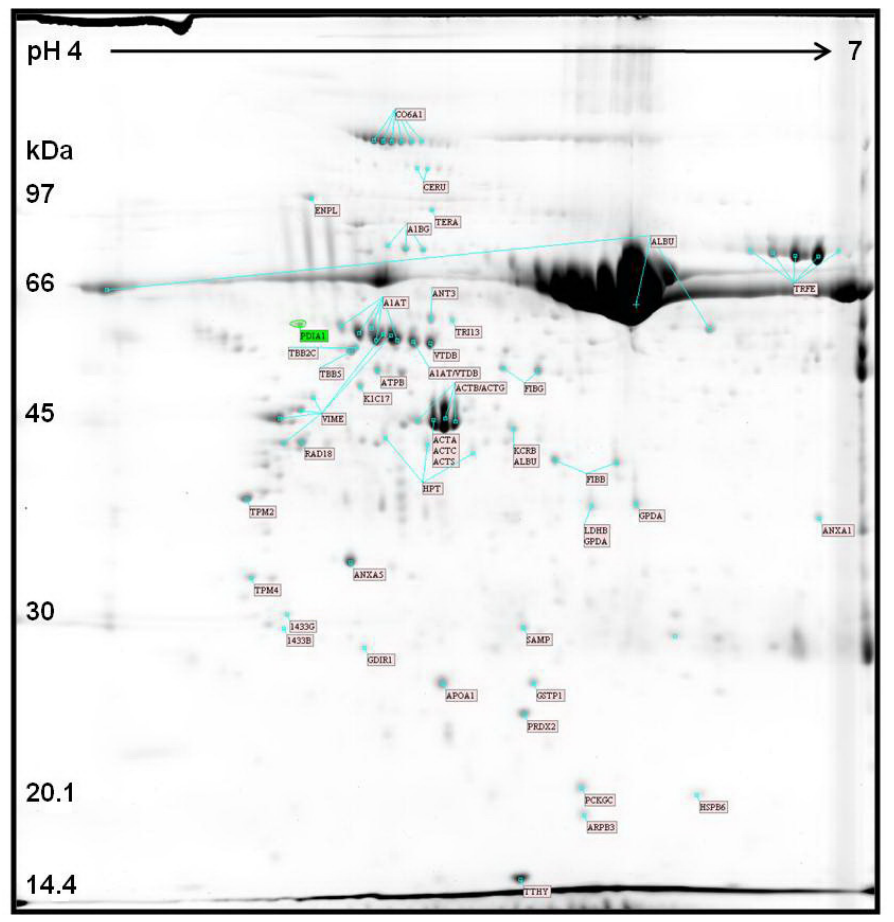

Figure 1. Reference gel obtained after 2-D electrophoresis. The protein spots are identified with the abbreviated name of the Swiss-Prot database.

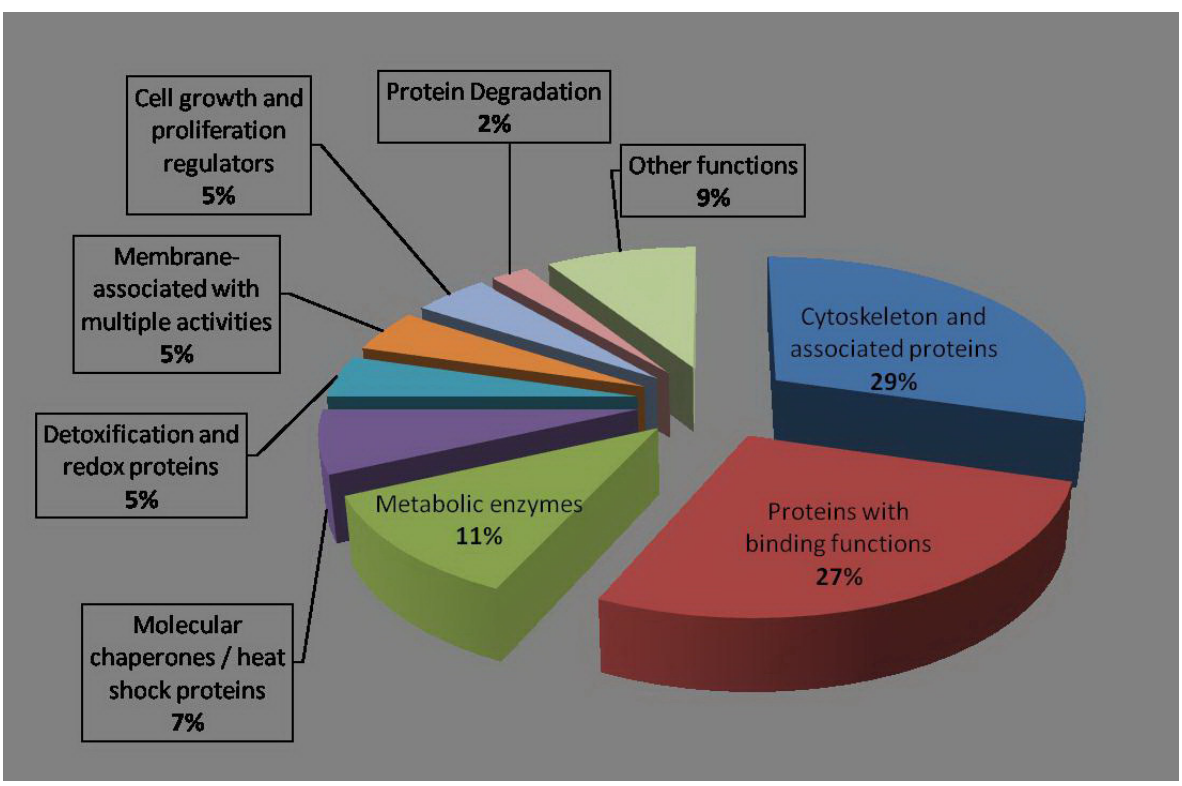

Figure 2. Functional classification of the identified proteins. 


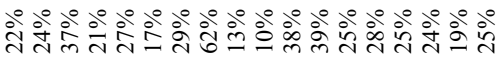

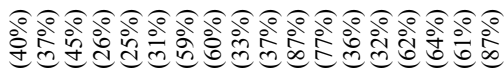
anm

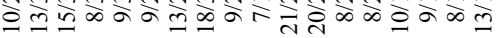

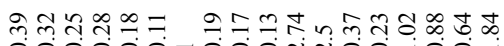

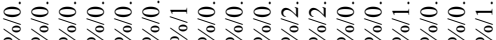

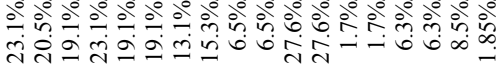

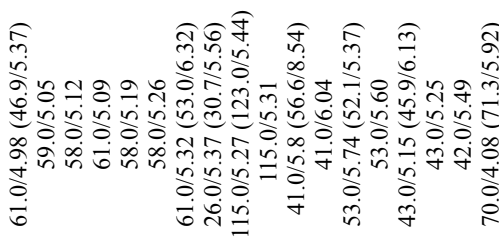

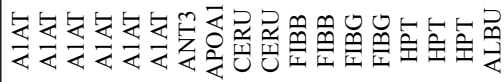

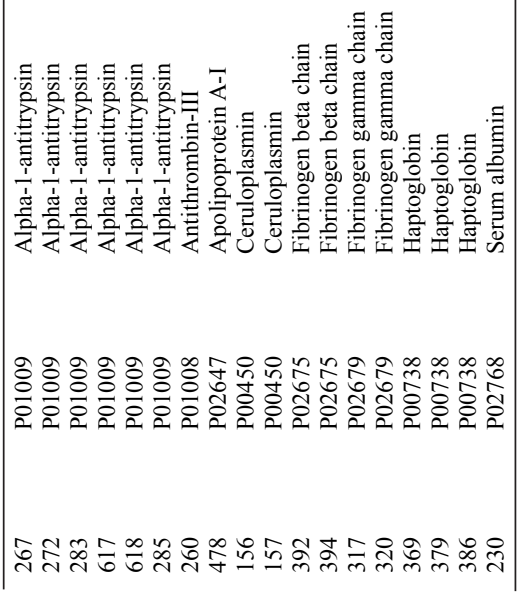


G.G. Costa et al.

2436

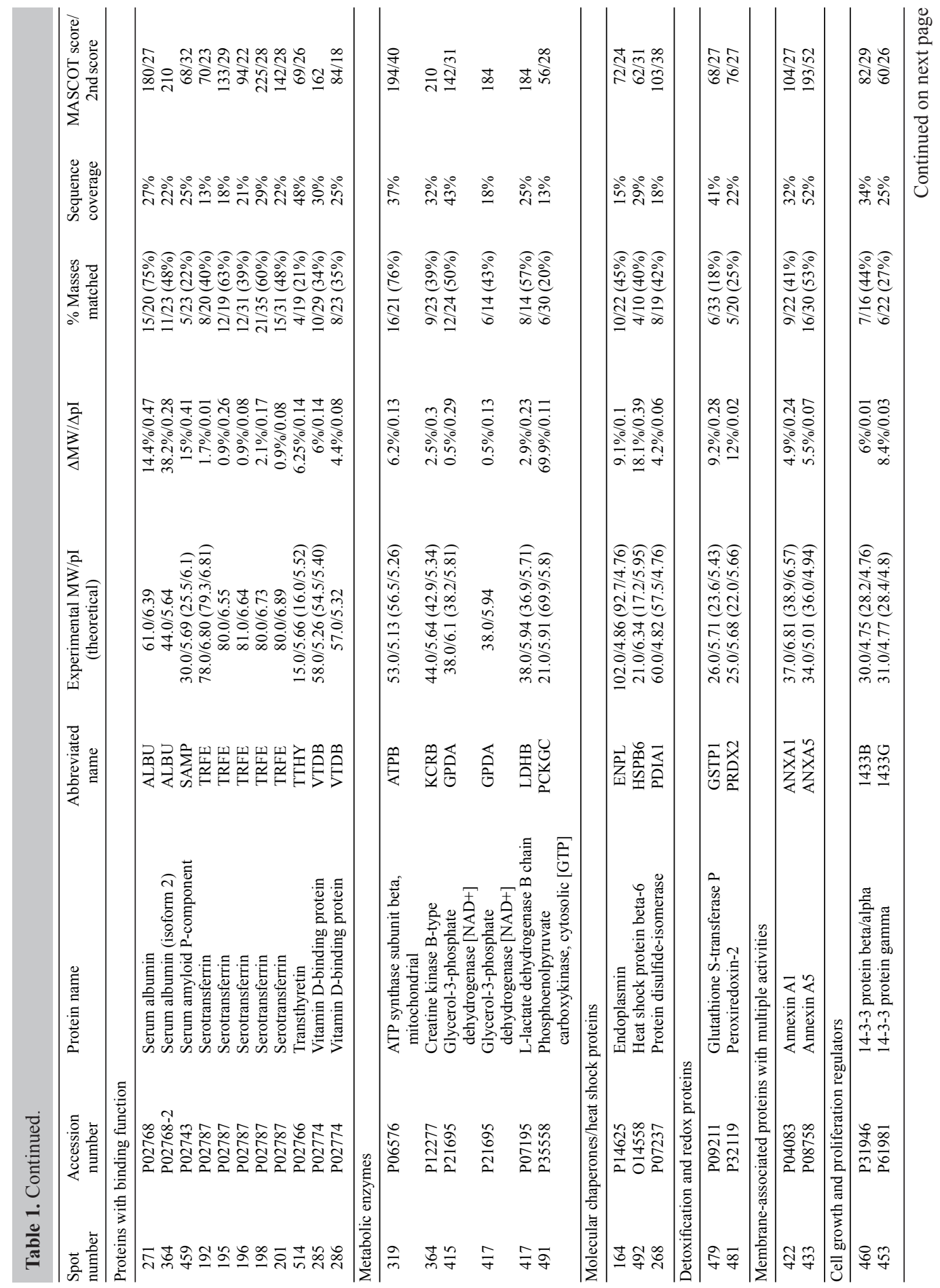

Genetics and Molecular Research 10 (4) 2430-2442 (2011)

CFUNPEC-RP www.funpecrp.com.br 
Proteomics of mammary tissue

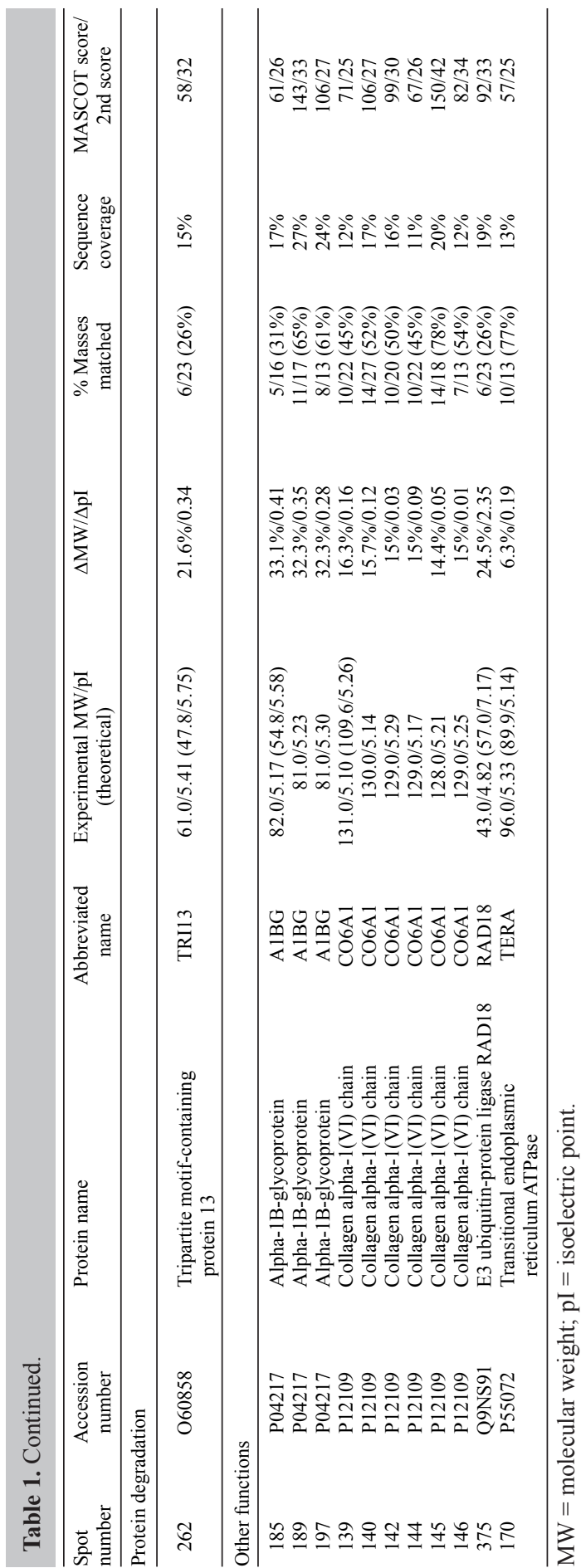




\section{Cytoskeleton and associated proteins}

Thirteen identified proteins from 17 spots composed this class. Some spots contained more than one protein, representing co-migrant proteins with similar primary structures or molecular weight. This is the largest class (30\% of the proteins).

The cytoskeleton is a complex and dynamic system. In general, cytoskeletal proteins polymerize to form long chains, giving the appearance of strand-like or fibrous structures. It is directly or indirectly involved in several important cellular processes, including cell polarity, adhesion, intracellular transport, signal transduction, and cell movement (Pucci-Minafra et al., 2006), which in turn play important roles in embryogenesis, wound healing, inflammation, and cancer metastasis (Eriksson et al., 2009). There are three general classes of cytoskeletal fibers: 1) microtubules, 2) intermediate filaments, and 3) actin filaments. The actin proteins are extremely conserved evolutionarily and are essential for eukaryotic cells. Because they are very similar, distinctions by peptide mass fingerprinting are difficult, and they are commonly identified in a single spot (Dupont et al., 2005; Pucci-Minafra et al., 2006). We identified three spots as actin, cytoplasmatic $1 / 2$ (ACTB/ACTG). They differ by just four amino acids and were detected together. The same occurred with actins in aortic smooth muscle, alpha cardiac muscle and alpha skeletal muscle (ACTA/ACTC/ACTS). All the different types of actins were considered in determining the total count of identified proteins.

Seven spots were identified as vimentin, an important structural component of the cytoskeleton and generally accepted as the cytoskeletal component responsible for maintaining cell integrity. Studies using knockout mice have revealed the involvement of this protein in a number of critical cellular processes related to the organization and regulation of proteins involved in adhesion, migration and cell signaling. Furthermore, it plays a significant role in supporting and anchoring the position of the organelles in the cytosol, providing flexibility to the cell (Eriksson et al., 2009).

\section{Proteins with binding function}

With 28 bands corresponding to 12 proteins and their isoforms, the class of proteins with binding functions $(27 \%)$ was the second most abundant. The proteins identified in this group were: antithrombin, alpha-1-antitrypsin (A1AT, six spots), serotransferrin (five spots), haptoglobin (three spots), serum albumin (three spots, including the isoform 2), fibrinogen beta chain (two spots), fibrinogen gamma chain (two spots), vitamin Dbinding protein (VTDB, two spots), ceruloplasmin (two spots), apolipoprotein A-I, serum amyloid P-component, and transthyretin. Many of these proteins have their binding function associated with the transport of molecules. A1AT and VTDB were identified in the same spot as a mixture.

The main function of human ceruloplasmin is to reduce molecular oxygen, transforming oxidized ferrous ions into a less toxic form, without releasing reactive oxygen species (Sokolov et al., 2006; Altamura et al., 2009). Serum albumin, which has as one of its principal functions regulation of osmotic blood pressure, is also the main zinc carrier in plasma (Deng et al., 2006; Lu et al., 2008). Serum albumin was present in a mixture with creatine kinase B-type (KCRB/albumin) above the acceptable range of $20 \%$ for the mass $(38.2 \%)$. We suggest that this protein corresponds to isoform 2 , generated by alternative splicing and with molecular 
mass equal to $47.36 \mathrm{kDa}$ (UniProtKB/SwissProt database). The MW variation for this isoform was $7 \%$, remaining within the acceptable range.

\section{Metabolic enzymes}

The group of metabolic enzymes (11\%) was composed of five spots corresponding to five enzymes: L-lactate dehydrogenase B chain (LDHB), KCRB, glycerol-3-phosphate dehydrogenase $[\mathrm{NAD}+]$ (GPDA), ATP synthase subunit beta, mitochondrial (ATPB) and phosphoenolpyruvate carboxykinase, cytosolic [GTP] (PCKGC). This last protein was identified with a score limit of 56 and sequence coverage of $13 \%$. The variation between the theoretical and experimental MW was 70\%. There are no reports of alternative splicing in the UniProtKB/SwissProt database. LDHB and GPDA were identified together as a mixture. Among these proteins, some are involved in the anaerobic glycolytic pathway and others are mitochondrial enzymes belonging to energy metabolism.

\section{Molecular chaperones/heat shock proteins}

Protein folding in the cell is aided by enzymes that speed up the process and chaperones that prevent aggregation. Misfolded proteins can obviously result in loss of function, besides forming large insoluble aggregates that also interfere in cellular function (Wilkinson and Gilbert, 2004). Molecular chaperones are an important group of heat shock proteins, and their expression is induced by cellular stress (Pucci-Minafra et al., 2006). The molecular chaperones/heat shock proteins class comprised $7 \%$ of the identified proteins. Three spots were analyzed, each one corresponding to a different protein: endoplasmin, small heat shock protein beta-6, and protein disulfide-isomerase. This group is underrepresented if we compare our study with some cancer proteomics reports (Pucci-Minafra et al., 2007; Kim et al., 2011) in which several proteins of this group are commonly overexpressed and constitute a target for therapy.

\section{Detoxification and redox proteins}

Proteins related to detoxification and redox proteins (4\%) are enzymes important for catabolism and cellular protection against metabolic stress (Pucci-Minafra et al., 2006). We found two proteins that represent this class: glutathione S-transferase P (GSTP1) and peroxiredoxin-2 (PRDX2). The GST family codes for enzymes essential to the detoxification process, reducing gluthatione and facilitating the excretion of many xenobiotics. GSTP1, located in chromosome 11q18, is polymorphic and may be of particular relevance in cancer susceptibility (Leichsenring et al., 2006). PRDX2 is a potent peroxide reductant; it is the third most abundant protein in the erythrocyte and plays a major role in the cell's oxidative defense, mainly in detoxifying endogenous-generated $\mathrm{H}_{2} \mathrm{O}_{2}$ (Johnson et al., 2010).

\section{Membrane-associated proteins with multiple activities}

Annexins I and $\mathrm{V}$ are the class of membrane-associated proteins with multiple 
activities (5\%). The annexins are involved in a wide range of functions both inside and outside cells. They belong to a class of proteins that interact with $\mathrm{Ca}^{2+}$ ions and with components of the membrane. These are properties that link annexins to many membranerelated events, such as the regulated organization of membrane domains and/or membrane/ cytoskeleton linkages, certain exocytic and endocytic transport steps, and the regulation of ion fluxes across membranes (Gerke et al., 2005).

\section{Cell growth and proliferation regulators}

The category of proteins involved in cell growth and proliferation regulation $(5 \%)$ was composed of two proteins, 14-3-3 beta/alpha (1433B) and gamma 14-3-3 (1433G), each corresponding to one spot. The 14-3-3 proteins exhibit a remarkable conservation of sequences between species and form a group of multifunctional proteins that bind to and modulate the function of several cellular proteins (Fu et al., 2000).

\section{Protein degradation}

The tripartite motif-containing protein 13 (TRI13) was the only protein identified in this class (2\%). It is encoded by the TRIM13 gene, which belongs to the TRIM family. Proteins of this family are involved in ubiquitination of damaged proteins or in excess. This signal causes the proteins to be routed to proteosomes (Meroni and Diez-Roux, 2005), a very important mechanism to ensure cell homeostasis.

\section{Other functions}

The class of proteins with other functions (9\%) was composed of 11 spots corresponding to four proteins and their isoforms: collagen alpha-1(VI) chain (CO6A1) (six spots), alpha-1B-glycoprotein (A1BG) (three spots), transitional endoplasmic reticulum ATPase (TERA), and E3 ubiquitin-protein ligase RAD18 (RAD18).

The CO6A1 and other proteins of the collagens superfamily are responsible for maintaining the integrity of various tissues. The protein TERA belongs to the AAA family (ATPases associated with different cellular activities), which is associated with several cellular processes, such as membrane fusion, protein degradation, organelle biogenesis, and cell cycle regulation (Meyer et al., 2000). According to the NCBI database, the A1BG is a plasmatic glycoprotein whose function remains unknown. Furthermore, according to the NCBI database, RAD18 is involved in post-replication repair of DNA damaged by UV.

\section{CONCLUSION}

Breast tissue is very complex due to the influence of various factors throughout life, and therefore it is difficult to establish a proteomic profile. We identified several proteins, including possible isoforms that constitute an important basis for future studies. The identification of these proteins and their isoforms help to explain the post-translational modifications responsible for the observed variation in the proteomic analyses. Many of the proteins identi- 
fied in this study have been reported as differentially expressed in relation to breast tumors such as vimentin, endoplasmin, small heat shock beta-6, disulfide isomerase and some cell growth, and proliferation regulators, suggesting the importance of including data on the characterization of non-tumoral breast contributing with novel information for subsequent studies on differential expression with tumor tissue.

\section{ACKNOWLEDGMENTS}

The authors are grateful to the Departamento de Bioquímica, UFPR for the assistance with the Maldi-Tof and to Dr Roseli Wassem for valuable technical suggestions. Research supported by CNPq (Conselho Nacional de Desenvolvimento Científico e Tecnológico, Brazil).

\section{REFERENCES}

Altamura C, Squitti R, Pasqualetti P, Gaudino C, et al. (2009). Ceruloplasmin/Transferrin system is related to clinical status in acute stroke. Stroke 40: 1282-1288.

Bradford MM (1976). A rapid and sensitive method for the quantitation of microgram quantities of protein utilizing the principle of protein-dye binding. Anal. Biochem. 72: 248-254.

Courtillot C, Plu-Bureau G, Binart N, Balleyguier C, et al. (2005). Benign breast diseases. J. Mammary Gland Biol. Neoplasia 10: 325-335.

Deng SS, Xing TY, Zhou HY, Xiong RH, et al. (2006). Comparative proteome analysis of breast cancer and adjacent normal breast tissues in human. Genomics Proteomics Bioinformatics 4: 165-172.

Dupont A, Corseaux D, Dekeyzer O, Drobecq H, et al. (2005). The proteome and secretome of human arterial smooth muscle cells. Proteomics 5: 585-596.

Eriksson JE, Dechat T, Grin B, Helfand B, et al. (2009). Introducing intermediate filaments: from discovery to disease. $J$. Clin. Invest. 119: 1763-1771.

Fu H, Subramanian RR and Masters SC (2000). 14-3-3 proteins: structure, function, and regulation. Annu. Rev. Pharmacol. Toxicol. 40: 617-647.

Gerke V, Creutz CE and Moss SE (2005). Annexins: linking $\mathrm{Ca}^{2+}$ signalling to membrane dynamics. Nat. Rev. Mol. Cell Biol. 6: 449-461.

Hondermarck H, Tastet C, El Yazidi-Belkoura I, Toillon RA, et al. (2008). Proteomics of breast cancer: the quest for markers and therapeutic targets. J. Proteome Res. 7: 1403-1411.

Johnson RM, Ho YS, Yu DY, Kuypers FA, et al. (2010). The effects of disruption of genes for peroxiredoxin-2, glutathione peroxidase-1, and catalase on erythrocyte oxidative metabolism. Free Radic. Biol. Med. 48: 519-525.

Kim SW, Kim S, Nam EJ, Jeong YW, et al. (2011). Comparative proteomic analysis of advanced serous epithelial ovarian carcinoma: possible predictors of chemoresistant disease. OMICS 15: 281-292.

Leichsenring A, Losi-Guembarovski R, Maciel ME, Losi-Guembarovski A, et al. (2006). CYP1A1 and GSTP1 polymorphisms in an oral cancer case-control study. Braz. J. Med. Biol. Res. 39: 1569-1574.

Lopez-Garcia MA, Geyer FC, Lacroix-Triki M, Marchió C, et al. (2010). Breast cancer precursors revisited: molecular features and progression pathways. Histopathology 57: 171-192.

Löster K and Kannicht C (2008). 2-Dimensional Electrophoresis: Detection of Glycosylation and Influence on Spot Pattern. In: Methods in Molecular Biology. Vol. 446, 2nd edn. Post-translational Modifications of Proteins: Tools for Functional Proteomics (Kannicht C, ed.). Human Press, Totowa, 199-214.

Lu J, Stewart AJ, Sadler PJ, Pinheiro TJ, et al. (2008). Albumin as a zinc carrier: properties of its high-affinity zinc-binding site. Biochem. Soc. Trans. 36: 1317-1321.

Mayr U, Mayr M, Yin X, Begum S, et al. (2005). Proteomic dataset of mouse aortic smooth muscle cells. Proteomics 5: 4546-4557.

Meroni G and Diez-Roux G (2005). TRIM/RBCC, a novel class of 'single protein RING finger' E3 ubiquitin ligases. Bioessays 27: 1147-1157.

Meyer HH, Shorter JG, Seemann J, Pappin D, et al. (2000). A complex of mammalian ufd1 and npl4 links the AAAATPase, p97, to ubiquitin and nuclear transport pathways. EMBO J. 19: 2181-2192.

Moreira JM, Cabezon T, Gromova I, Gromov P, et al. (2010). Tissue proteomics of the human mammary gland: towards 
an abridged definition of the molecular phenotypes underlying epithelial normalcy. Mol. Oncol. 4: 539-561.

Navarrete MA, Maier CM, Falzoni R, Quadros LG, et al. (2005). Assessment of the proliferative, apoptotic and cellular renovation indices of the human mammary epithelium during the follicular and luteal phases of the menstrual cycle. Breast Cancer Res. 7: R306-R313.

Pucci-Minafra I, Cancemi P, Fontana S, Minafra L, et al. (2006). Expanding the protein catalogue in the proteome reference map of human breast cancer cells. Proteomics 6: 2609-2625.

Pucci-Minafra I, Cancemi P, Marabeti MR, Albanese NN, et al. (2007). Proteomic profiling of 13 paired ductal infiltrating breast carcinomas and non-tumoral adjacent counterparts. Proteomics Clin. Appl. 1: 118-129.

Ramos CMP and Bora PS (2004). Functional characterization of acetylated Brazil nut (Bertholletia excelsa HBK) kernel globulin. Cienc. Tecnol. Aliment. 24: 134-138.

Sokolov AV, Pulina MO, Zakharova ET, Susorova AS, et al. (2006). Identification and isolation from breast milk of ceruloplasmin-lactoferrin complex. Biochemistry 71: 160-166.

Toillon RA, Lagadec C, Page A, Chopin V, et al. (2007). Proteomics demonstration that normal breast epithelial cells can induce apoptosis of breast cancer cells through insulin-like growth factor-binding protein-3 and maspin. Mol. Cell Proteomics 6: 1239-1247.

Wilkinson B and Gilbert HF (2004). Protein disulfide isomerase. Biochim. Biophys. Acta 1699: 35-44.

Zhu K, Zhao J, Lubman DM, Miller FR, et al. (2005). Protein pI shifts due to posttranslational modifications in the separation and characterization of proteins. Anal. Chem. 77: 2745-2755. 